\title{
Administration of a Peptide Inhibitor of $\alpha 4$-Integrin Inhibits the Development of Experimental Autoimmune Uveitis
}

\author{
Andrea P. Martín, ${ }^{1,2,3}$ Luciana Vieira de Moraes, ${ }^{1,2}$ Carlos E. Tadokoro, ${ }^{1}$ \\ Alessandra G. Commodaro, ${ }^{1}$ Enrique Urrets-Zavalia, ${ }^{4}$ Gabriel A. Rabinovich, ${ }^{5}$ \\ Julio Urrets-Zavalia, ${ }^{4}$ Luiz V. Rizzo, ${ }^{1,6,7}$ and Horacio M. Serra ${ }^{3}$
}

PurPose. Recruitment of lymphocytes into the retina and to the vitreous during the development of experimental autoimmune uveitis (EAU) is governed by factors such as the state of activation of inflammatory cells and the repertoire of adhesion molecules expressed by the local vascular endothelia. $\alpha 4$ Integrins and their receptors play an important role during homing of cells to the inflammatory site. In the present study, the effect of $\alpha 4$-integrin inhibitor on the development of EAU was investigated.

Methods. EAU was induced either by immunizing B10.RIII mice with the 161-180 peptide or by adoptive transfer of interphotoreceptor retinoid-binding protein (IRBP)-specific uveitogenic T cells. Animals were treated with an active peptide inhibitor ( $\alpha 4$-api) or a peptide control at different time points after induction of disease. EAU was evaluated by histology 21 to 49 days after immunization. Antigen-specific cell proliferation was evaluated by thymidine incorporation. Cytokine synthesis in culture supernatants and anti-IRBP-specific serum IgG1 and IgG2a were evaluated by ELISA. Delayed-type hypersensitivity was evaluated by ear challenge 2 days before the termination of the experiment.

Results. Treatment with $\alpha 4$-api had a significant ameliorating effect on EAU. The anti-IRBP antibody response and cellular proliferation were not affected by the treatment, whereas delayed-type hypersensitivity was significantly diminished. Cyto-

From the ${ }^{1}$ Department of Immunology, Biomedical Sciences Institute, University of São Paulo, São Paulo, Brazil; ${ }^{3}$ Departamento Bioquímica Clínica, Inmunología, Facultad Cs, Químicas, UNC, Argentina; ${ }^{4}$ Clínica Reina Fabiola, Córdoba, Argentina; ${ }^{5}$ División Inmunogenética, Hospital de Clínicas "José de San Martín," Universidad de Buenos Aires, Buenos Aires, Argentina; 'LIM-60, University of São Paulo Medical School and Fundação Zerbini, São Paulo, Brazil; and ${ }^{7}$ Instituto de Investigação em Imunologia (iii), Ministério da Ciência e Tecnologia, Salvador, Brazil.

${ }^{2}$ Contributed equally to the work and therefore should be considered equivalent authors.

Supported by grants from Fundação de Amparo a Pesquisa do Estado de São Paulo (FAPESP) and Brazilian Ministry of Science and Technology (MCT). LVR is a recipient of a personal grant for scientific achievement from Conselho Brasileiro de Desenvolvimento Científico e Tecnológico (CNPq).

Submitted for publication April 14, 2004; revised August 6, November 5, and December 15, 2004, and February 14, 2005; accepted February 18, 2005.

Disclosure: A.P. Martín, None; L. Vieira de Moraes, None; C.E. Tadokoro, None; A.G. Commodaro, None; E. Urrets-Zavalia, None; G.A. Rabinovich, None; J. Urrets-Zavalia, None; L.V. Rizzo, None; H.M. Serra, None

The publication costs of this article were defrayed in part by page charge payment. This article must therefore be marked "advertisement" in accordance with 18 U.S.C. $\$ 1734$ solely to indicate this fact.

Corresponding author: Luiz V. Rizzo, Department of Immunology, University of São Paulo, Av. Prof. Lineu Prestes, São Paulo, SP, Brazil CEP 05508-900; 1vrizzo@icb.usp.br. kine synthesis was not changed by treatment, except for a decrease in IL-10 levels.

Conclusions. The results show that small-molecule inhibitors of $\alpha 4$-integrins can act therapeutically in EAU, possibly by interfering with cell adhesion events involved in the development of the disease. (Invest Ophthalmol Vis Sci. 2005;46:2056-2063) DOI:10.1167/iovs.04-0418

Cxperimental autoimmune uveitis (EAU) is an organ-specific, C.cell-mediated disease that is characterized by inflammation and subsequent destruction of the neural retina and adjacent tissues. EAU can be induced in rodents and primates by immunization with one of several retinal antigens. Disease can also be induced by adoptive transfer of retinal antigen-specific $\mathrm{CD}^{+}{ }^{+} \mathrm{T}$ cells in syngeneic rodents. ${ }^{1}$ The pathologic and clinical courses of EAU in the mouse model closely resemble those in human uveitis of putative autoimmune etiology. ${ }^{2,3}$ Therefore, the study of immunologic mechanisms affecting EAU can help in the understanding of human ocular autoimmunity as well as other organ-specific, T-cell-mediated autoimmune diseases.

In EAU, damage to the eye is caused by infiltrating lymphocytes, macrophages, and polymorphonuclear cells. Recruitment of these cells is a fundamental step in the development of the disease. The lymphocyte population that migrates to the eye is constituted by both retinal antigen-specific lymphocytes and nonspecific cells. ${ }^{4-6}$ In general, lymphocyte extravasation is governed by a variety of factors, such as the state of cell activation and the repertoire of adhesion molecules expressed by the local vascular endothelia. ${ }^{7,8}$ Lymphocyte traffic into the retina, however, is controlled not only by these factors but also by the group of components that confer immune privilege to the eye. ${ }^{9}$ One of the first steps in the pathogenesis of EAU is the binding of leukocytes to the vascular endothelium of the blood-retinal barrier (BRB). This initial interaction is followed by diapedesis of the leukocytes and their subsequent migration into the retina and the choroid's parenchyma. ${ }^{10-12}$

$\mathrm{T}$ cells play a crucial role in the induction of $\mathrm{EAU}^{1,13}$ and in later stages of the disease when Th1-type cells and macrophages invade the retina and destroy the photoreceptor cell layer and the choroid, causing ocular damage. ${ }^{13,14}$ Even though the role of the integrin family of adhesion molecules has not been studied extensively in EAU, it has been demonstrated in experimental allergic encephalomyelitis (EAE) that the expression of very late antigen (VLA)- 4 ( $\alpha 4 \beta 1)$ is required for encephalitogenic T-cell clones to enter the central nervous system (CNS) and induce disease. ${ }^{15,16}$ Furthermore, treatment with monoclonal antibodies (mAbs) against $\alpha$-integrins suppresses clinical signs and cell recruitment to the CNS in some EAE models. ${ }^{17,18}$

The extensive distribution of adhesion molecules on the endothelium of the vessels in the retina and iris in biopsy specimens obtained from patients with uveitis and the contri- 
bution of integrins to lymphocyte binding to these vessels has suggested that they play an important role in the development of the disease. ${ }^{19,20}$ It has been suggested that lymphocyte adhesion to the retinal vessels is dependent on CD29 expression (the common chain of $\beta 1$-integrins), whereas expression of CD11a/CD18 or CD49d is not as crucial. ${ }^{21}$ It has also been shown that the expression of vascular cell adhesion molecule (VCAM)-1 and lymphocyte function-associated antigen (LFA)-1 in the vascular endothelium of the iris from patients with uveitis is increased, as well as the number of intercellular adhesion molecule (ICAM)-1 and VLA-4-positive cells. ${ }^{19}$ B10.A mice immunized with interphotoreceptor retinoid-binding protein (IRBP) have an increased expression of ICAM-1 in the eyes before histologic evidence of inflammation. Monoclonal antibodies against ICAM-1 and LFA-1 were effective in inhibiting EAU in these animals. ${ }^{22}$ In addition, an in vitro study in a rat model has confirmed that lymphocyte adhesion and transmigration across monolayers of IFN- $\gamma$-activated retinal pigmented epithelial (RPE) cells are inhibited by mAbs against VLA- 4 and VCAM-1 in a rat model. ${ }^{23}$ Blood vessels in the retina also express VCAM-1 during the development of EAU, which seems to be involved in lymphocyte migration into the eye. ${ }^{20,23}$

VLA- 4 and $\alpha 4 \beta 7$-integrins can interact with the CS- 1 domain of fibronectin (Fn) and VCAM-1. ${ }^{24,25}$ We and others have reported that CS-1 Fn is expressed in the blood vessels under different inflammatory conditions in which this molecule can be involved in cell-cell interactions. ${ }^{25,26}$ Interactions of VLA-4 with both of these ligands-VCAM-1 and Fn-can be blocked by peptides containing the CS-1 motif. ${ }^{27-29}$ Because these peptides can interfere in the binding activity of VLA-4, the inhibition of $\alpha 4$-mediated adhesion may be an attractive treatment to prevent the development of EAU. Modified peptide inhibitors have recently been used with chemical adaptations that make them more suitable for clinical application ${ }^{30-32}$ and in the treatment of different inflammatory diseases in experimental models. ${ }^{27,33-36}$

In the present study, we investigated the role of an $\alpha 4$ integrin inhibitor peptide, a CS-1 ligand mimetic, on the course of actively induced EAU in B10.RIII mice.

\section{Materials ANd Methods}

\section{Animals}

Six- to 8-week-old B10.RIII mice were obtained from our own animal facilities at the University of São Paulo. All animals were housed under specific pathogen-free conditions and treated according to the ARVO Statement for the Use of Animals in Ophthalmic and Vision Research. The animal care and use committee at the Institute of Biomedical Sciences (University of São Paulo) approved all the procedures used in the study.

\section{Antigen and Reagents}

Peptide SGIPYIISYLHPGNTILHVD representing residues 161-180 of IRBP was synthesized using Fmoc chemistry on a peptide synthesizer (Pioneer, Applied Biosystems [ABI], Foster City, CA). Pertussis toxin (PTX) and CFA were purchased from Sigma-Aldrich (St. Louis, MO). The active $\alpha$-integrin inhibitor phenylacetyl-L-leucyl-L-aspartyl-L-phenylalanyl-morpholineamide ( $\alpha 4$-api) and the scrambled version (inactive control agent) were generated by Cytel Corp. (San Diego, CA). These compounds were dissolved in sterile PBS $(0.01 \mathrm{M}$; pH 7.4) at a concentration of $10 \mathrm{mg} / \mathrm{mL}$ and stored at $-70^{\circ} \mathrm{C}$ before use.

\section{Induction of EAU}

Mice were immunized by a subcutaneous injections at the base of the tail and neck with $50 \mu \mathrm{g}$ IRBP (161-180) emulsified in $0.2 \mathrm{~mL}$ complete Freund's adjuvant (CFA; vol/vol). At the same time, they were injected intraperitoneally with $0.40 \mu \mathrm{g}$ PTX in $0.1 \mathrm{~mL}$ DMEM, as an additional adjuvant. Alternatively, animals received intravenously $10^{6} \mathrm{CD}^{+}{ }^{+} \mathrm{T}$ cells from a uveitogenic T-cell line described previously. ${ }^{37}$ Before injection, the uveitogenic cells were stimulated in vitro with $30 \mu \mathrm{g} / \mathrm{mL}$ IRBP for 48 hours.

\section{Anti-VLA-4 Treatment}

Animals were injected intraperitoneally with $10 \mathrm{mg} \alpha 4$-api or an inactive peptide control in some experiments, in $0.1 \mathrm{~mL}$ during the afferent (days 2, 4, and 6) or efferent (days 14, 16, and 18) phase after immunization (day 0). In some experiments, animals were treated on days $14,16,18,21,25,29$, and 31 after immunization or only on days $21,25,29$, and 31 after immunization. In these experiments, eyes were enucleated 35 days after immunization. In adoptive transfer experiments, animals were treated with the same dose of $\alpha 4$-api on days 1, 3, 5,7 , and 9 after transfer of uveitogenic T cells. In one set of experiments, animals were killed 49 days after immunization.

\section{Delayed-Type Hypersensitivity}

Two days before the termination of an experiment, mice received 10 $\mu \mathrm{g}$ of IRBP in $10 \mu \mathrm{L}$ intradermically in the left ear. The other ear was injected with the same volume of PBS. Ear swelling was measured at the termination of the experiment ( 48 hours later) with an electronic micrometer. Delayed-type hypersensitivity (DTH) results are expressed as antigen-specific swelling, calculated as the difference between the thicknesses of the IRBP- and the PBS-injected ears.

\section{Fundoscopy}

Animals received a drop of phenylephrine $10 \%$ and tropicamide $1 \%$ in each eye. Five minutes after administration of the mydriatic drug, animals were anesthetized, and examination of the eye fundus was performed with a stereoscope (MZ08; Leika, Heidelberg, Germany) under $20 \times$ magnification. Mice were scored for uveitis according to the criteria described in the next section.

\section{Scoring of EAU}

Eyes were collected and prepared for histologic evaluation at the end of each experiment. The eyes were immersed for 1 hour in phosphatebuffered glutaraldehyde $4 \%$, transferred into phosphate-buffered formaldehyde $10 \%$ for 24 hours, and placed in ethanol $70 \%$ until processing. Fixed and dehydrated tissue was embedded in paraffin wax, and 4- to $6-\mu \mathrm{m}$ sections were cut through the pupillary-optic nerve plane. Sections were stained by hematoxylin and eosin. Presence or absence of disease was evaluated in a double-blind fashion in six sections cut at different levels in each eye. The severity of EAU was scored on a scale of 0 (no disease) to 4 (maximum disease) in half-point increments, according to lesion type, size, and number, by using a semiquantitative system described previously. ${ }^{38,39}$ In brief, the minimal criterion to score an eye as positive by histopathology was inflammatory cell infiltration of the ciliary body, choroid, or retina (EAU grade 0.5 ). Progressively higher grades were assigned for the presence of discrete lesions in the tissue, such as vasculitis, granuloma formation, retinal folding and/or detachment, and photoreceptor damage.

\section{Lymphocyte Proliferation}

Draining lymph nodes were collected and pooled within each group at the end of each experiment ( 21 days after immunization). Triplicate cultures of $5 \times 10^{5}$ cells/well were stimulated with $30 \mu \mathrm{g} / \mathrm{mL}$ IRBP in 96-well flat-bottomed plates in DMEM containing 10\% FCS and supplemented with $10^{-5}$ M 2-mercaptoethanol, $2 \mathrm{mM}$ L-glutamine, $0.1 \mathrm{mM}$ nonessential amino acids, $50 \mu \mathrm{g} / \mathrm{mL}$ gentamicin, $1 \mathrm{mM}$ sodium pyruvate, and $20 \mathrm{mg} / \mathrm{mL}$ of $\alpha$-methyl-mannopyranoside, to quench any residual concanavalin A remaining from the chromatography preparation of IRBP. The cell cultures were incubated for 96 hours and pulsed with $\left[{ }^{3} \mathrm{H}\right]$ thymidine $(0.5 \mu \mathrm{Ci} /$ well $)$ during the last 18 hours of incuba- 
tion. The results are given as a stimulation index (SI), calculated as follow, with CPM denoting counts per minute:

$$
\mathrm{SI}=\frac{\mathrm{CPM} \text { in stimulated cultures }}{\mathrm{CPM} \text { in cultures without stimulation }}
$$

\section{Determination of Cytokine Production in Lymphocyte Cultures}

Lymph node cells harvested on the day the animals were killed were cultured at $10^{6}$ cells/well and stimulated with $30 \mu \mathrm{g} / \mathrm{mL}$ IRBP. Supernatants were collected for cytokine analysis after 24 or 48 hours and stored at $-80^{\circ} \mathrm{C}$ until assayed. The levels of IFN- $\gamma$ and IL-4, $-5,-10,-12$, and -18 were evaluated by ELISA, using antibody pairs from BD-Pharmingen (La Jolla, CA) or ELISA kits from Pierce Biotechnology, Inc. (Rockford, IL). All materials were used according to the manufacturers instructions.

\section{Assay for IRBP-Specific Antibodies}

Anti-IRBP IgG1 and IgG2a isotype levels were determined by ELISA, as previously described. ${ }^{40}$ Briefly, 96-well microtiter plates (Corning Costar, Corning, NY) were coated with IRBP at $1 \mu \mathrm{g} / \mathrm{mL}$ for 4 hours at room temperature (RT), blocked with PBS-BSA 1\% (Sigma-Aldrich) for 1 hour at RT, washed twice with PBS and incubated for 2 hours with serum samples. Plates were washed again and developed with horseradish-peroxidase-conjugated rat anti-mouse IgG1 or rat anti-mouse IgG2a (Southern Biotechnology Associates, Birmingham, AL) for 1 hour at RT. Plates were washed and incubated with the substrate $(0.1 \mathrm{M}$ citric acid, $0.2 \mathrm{M} \mathrm{Na}_{2} \mathrm{HPO}_{4}[\mathrm{pH} 5.0], 20 \mu \mathrm{L} \mathrm{H}_{2} \mathrm{O}_{2}$, and $20 \mathrm{mg} o-$ phenylenediamine). The concentration of anti-IRBP Ab was estimated using standards curves constructed by coating wells with anti-Ig $\mathrm{Ab}$ against the appropriate isotype and adding polyclonal Ig standards of the corresponding isotype.

\section{Statistical Analysis}

Results are representative of two or three independent experiments. Statistical analysis of EAU scores was performed using the SnedecorCochran test for linear trends in proportion. ${ }^{41}$ Each mouse (average of both eyes) was treated as one statistical event. Results were considered significant when $P<0.05$.

\section{Results}

\section{Effect of an $\alpha$ 4-Integrin Inhibitor on the Development of IRBP-Induced EAU}

Disease was induced in B10.RIII mice as described in the Materials and Methods section. Animals were treated intraperitoneally with either $\alpha 4$-api or the control peptide during the afferent (days 2, 4, and 6) or efferent phases of the disease (days 14, 16, and 18). Mice from the control group became clinically ill and showed moderate to severe signs of EAU in histopathologic examination on day 21. Grading of the eyes showed that treatment with $\alpha 4$-api during the efferent phase significantly ameliorated the severity of the disease (mean EAU score of $1.05 ; P=0.042$ when compared with the control animals; Fig. 1A). By contrast, mice from the group treated with $\alpha 4$-api during the afferent phase of disease exhibited EAU of a grade similar to that in the control animals (scores 2.0 and 2.5 , respectively). Histopathology of the eyes of the control group on day 21 showed retinal disorganization; photoreceptor destruction; inflammatory cells in the vitreous, uvea, and retina; retinal vasculitis; and granuloma formation (Fig. 1B, right). In contrast, mice treated with $\alpha 4$-api during the efferent phase showed a normal retinal architecture (Fig. 1B, left). When only the animals that had EAU were analyzed by fundoscopy, disease onset was not shown to be significantly affected by treatment with $\alpha 4$-api. Disease onset in the control group

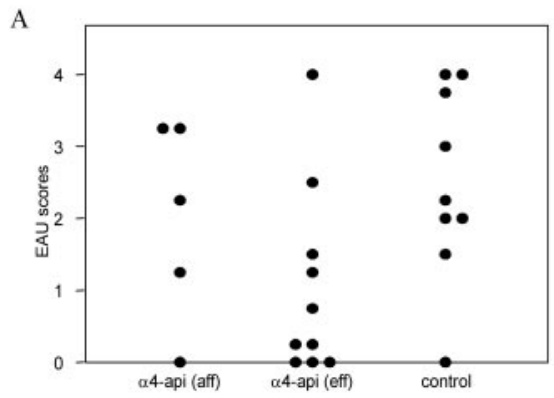

B

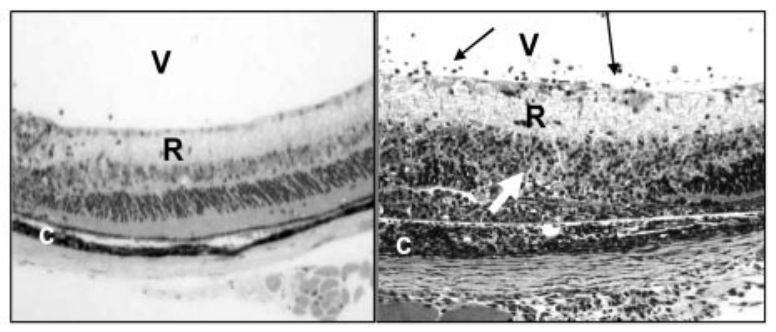

FigurE 1. The $\alpha 4$-integrin inhibitor suppresses the clinical signs of actively induced EAU. B10.RIII mice were immunized with $50 \mu \mathrm{g}$ of IRBP (161-180) on day 0 and treated with $10 \mathrm{mg}$ intraperitoneal $\alpha 4$-api or a peptide control on days 2,4 , and 6 (afferent phase) or days 14, 16, and 18 (efferent phase). Control animals received $10 \mathrm{mg}$ of an inactive peptide control on days 2, 4, 6, 14, 16, and 18. Eyes were collected for histopathology 21 days after immunization. (A) EAU scores were assigned on a scale from 0 to 4 according to the extent of inflammation and tissue damage. Each point represents one mouse (average of both eyes). Data are a compilation of results in two independent experiments. Mice treated with $\alpha 4$-api ameliorated the ocular inflammatory response $(p<0.05)$. Horizontal axis: Data represent the mean severity of the disease. (B) Histopathology of EAU showing a picture representative of each group of animals. Right: control mouse. Note the loss of the photoreceptor layer, retinal detachment (R), inflammatory cells (thin arrows) in the vitreous (V) and subretinal space, and retinal granuloma formation (thick arrow) Left: mouse treated with $\alpha 4$-api. Note the well-preserved retinal architecture. Magnifications: (right) $\times 400 ;($ left $) \times 100$.

was between days 8 and 13. In mice treated in the afferent phase, it was between days 9 and 14; and in mice treated in the efferent phase it was between days 10 and 14 . The effect of $\alpha 4$-api during the efferent phase of disease was confirmed by its effectiveness in preventing the development of EAU in mice that received uveitogenic T cells intravenously (Fig. 2). Animals received $10^{6}$ uveitogenic T cells. Eyes were harvested 14 days after immunization, which corresponds to the peak of disease in this adoptive transfer model. Treatment with the peptide resulted in amelioration of disease whether animals received it immediately after adoptive transfer (days 1, 3, and 5), or later (days 5, 7, and 9). These results suggest that the effect of the inhibitor is, at least in part, due to a blockade in the migration of activated $\mathrm{T}$ cells to the retina.

To test whether treatment during the efferent phase would simply delay the onset of disease, we observed animals immunized with a uveitogenic dose of IRBP for 35 days after immunization. Results are presented in Figure 3. As can be seen, treatment with $\alpha 4$-api in the efferent phase of disease was still effective in protecting against disease during this period, which suggests that treatment in the efferent phase does not simply delay the onset of disease, although continuous treatment is necessary to achieve the maximal effect. It is interesting to note that if treatment with $\alpha 4$-api started after the disease peaked (days 21-31, four-dose treatment) it was less effective than prolonged treatment from the efferent phase until day 31 (days 14-31, seven-dose treatment). Since the 


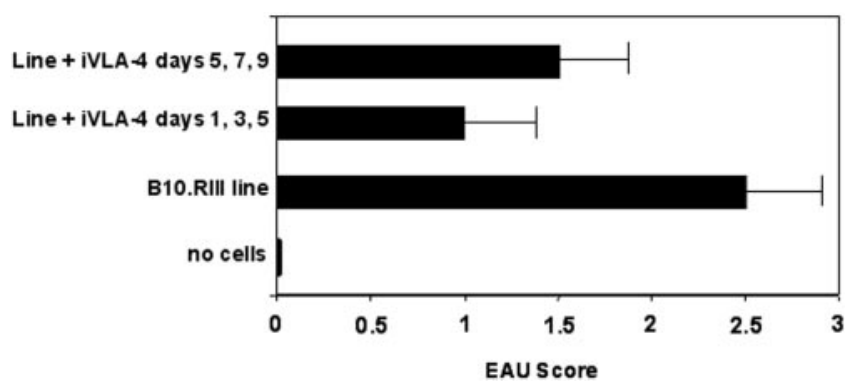

FIGURE 2. The $\alpha 4$-integrin inhibitor peptide suppressed EAU induced by adoptive transfer. B10.RIII mice received $10^{6}$ cells from a uveitogenic T-cell line on day 0 or not and were treated with $10 \mathrm{mg} \alpha 4$-api intraperitoneally on days 1,3 , and 5 (eight mice) or days 5,7 , and 9 (seven mice). Eyes were enucleated and analyzed for EAU by histology 14 days after adoptive transfer. EAU scores were determined as described in Materials and Methods. Data represent the mean disease score; error bars are the standard deviation. Mice treated with $\alpha 4$-api in both regimens showed an amelioration of the ocular inflammatory response $(P<0.05)$.

necessity for continuous treatment to maintain protection could be related to the development of tolerance to the inhibitor, we decided to treat mice in the afferent and efferent phases as described previously, either with $\alpha 4$-api or with control peptide and evaluated them for EAU grade 49 days after immunization. Results indicated that mice treated with the control peptide in either phase of EAU development displayed significant disease scores $(2.5 \pm 1$, with $100 \%$ incidence of disease, $6 / 6$ mice). Mice treated with $\alpha 4$-api in the afferent phase of disease had slightly lower disease grades $(2.0 \pm 0.5$ with $70 \%$ incidence, $7 / 10$ mice), and animals treated in the efferent phase showed even lower grades $(1.5 \pm 0.5$ with $70 \%$ incidence, $7 / 10$ mice). Compared with disease grades at day 21 , the data suggest that continuous treatment is necessary to obtain the maximal effect of the VLA- 4 inhibitor, although short-term treatment during the efferent phase has some longterm protective effects.

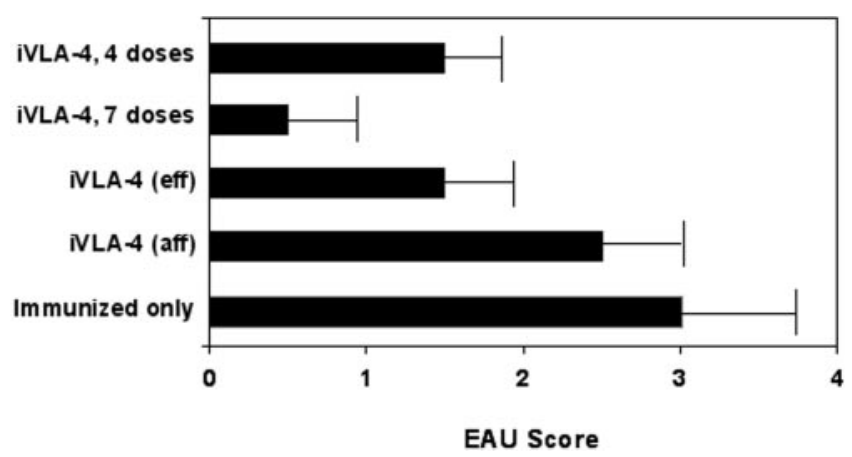

Figure 3. Continuous treatment with the VLA-4 peptide inhibitor was necessary for maintenance of the protective effect. B10.RIII mice (five in each group) were immunized with $50 \mu \mathrm{g}$ of IRBP (161-180) on day 0 and treated with $10 \mathrm{mg} \alpha 4$-api intraperitoneally on the afferent phase (aff) or efferent (eff) phase as described in Materials and Methods. In addition, animals were treated with four doses of $\alpha 4$-api (days $21,25,29$, and 31 after immunization; eight mice) or with seven doses (days 14, 16, 18, 21, 25, 29, and 31 after immunization; seven mice). Eyes were collected for histopathology 35 days after immunization, and the EAU scores determined. Data represent the mean disease score; error bars: standard deviation. Mice treated with $\alpha 4$-api in all regimens showed an amelioration of the ocular inflammatory response $(P<0.05)$, except for mice treated on the afferent phase.
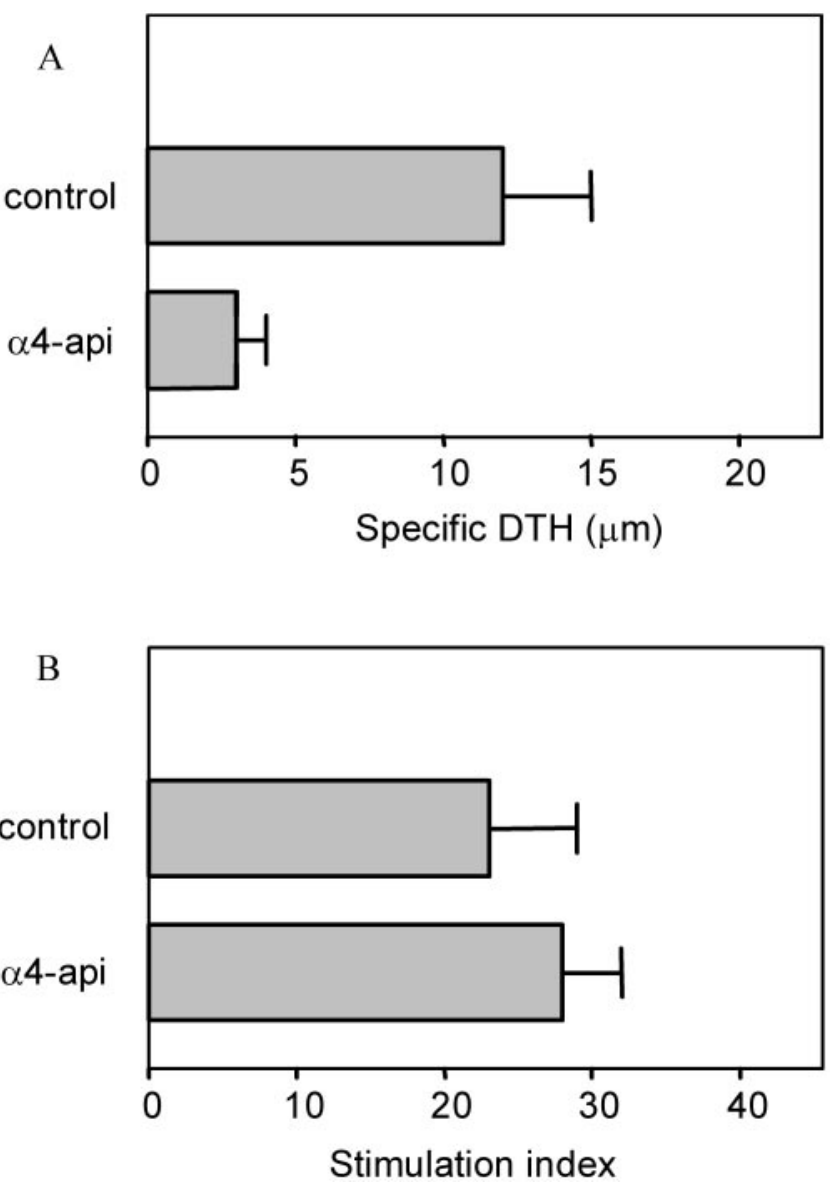

FIGURE 4. $\quad \alpha 4$-Integrin inhibitor reduces DTH, but has no effect on the proliferative response to IRBP. (A) Immunized B10.RIII mice treated or not treated with $\alpha 4$-integrin inhibitor in the efferent phase were tested for DTH to IRBP by intradermal injections of $10 \mu \mathrm{g}$ IRBP in one ear and PBS in the other ear 2 days before the termination of the experiment. After 48 hours, ear swelling was measured. DTH response was reduced in mice treated with $\alpha 4$-api $(P<0.05)$. DTH results are expressed as antigen-specific swelling and calculated as the difference between the thickness of the IRBP- and the PBS-injected ears. Results are expressed as mean $\pm \mathrm{SD}$. (B) The lymphoproliferative response to IRBP was determined 21 days after immunization. Draining lymph node cells were collected and stimulated in vitro with $30 \mu \mathrm{g} / \mathrm{mL}$ IRBP. Cultures were incubated for 96 hours and pulsed with $\left[{ }^{3} \mathrm{H}\right]$ thymidine for the last 18 hours. Proliferation is represented as a stimulation index \pm SD. Results are expressed as the mean \pm SD and represent the average of 15 mice in the treated group and 12 mice in the control group, in three separate experiments $\left({ }^{*} P<0.05\right)$.

\section{Effect of $\alpha 4$-Api on DTH and the Proliferative Response to IRBP}

Because treatment with $\alpha 4$-api during the efferent phase of the disease resulted in a blockade of EAU development, we next investigated the effects of the $\alpha 4$-api on the DTH response to IRBP and the specific proliferative response. Ear challenge for DTH was performed 19 days after immunization in mice treated with $\alpha 4$-api and in control subjects in the efferent phase of the disease. Swelling of the ear was significantly less prominent in the $\alpha 4$-api-treated mice, with a fourfold reduction in the DTH response $(P<0.05)$ when compared with the control group (Fig. 4A). In contrast, the proliferative response to IRBP on day 21 after immunization in $\alpha 4$-api-treated mice was unchanged compared with the control animals (Fig. 4B). Because we have not tested the DTH response in control mice treated only on days 18 and 20, it is possible that the exuberant 


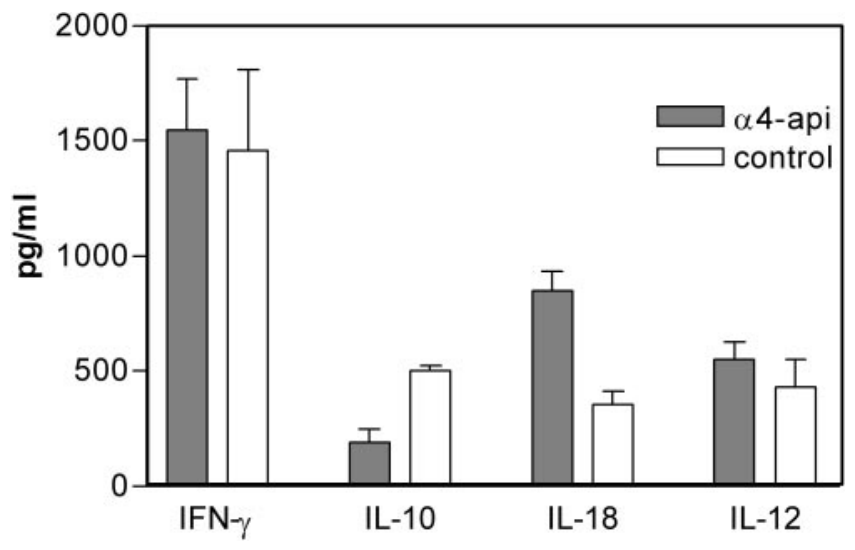

FIGURE 5. Antigen-specific cytokine production in lymph node cells from B10.RIII mice treated or not treated with an $\alpha 4$ peptide inhibitor at the efferent phase. Draining lymph node cells were collected 21 days after immunization, pooled within each group, and stimulated with $30 \mu \mathrm{g} / \mathrm{mL}$ IRBP for 24 or 48 hours. Supernatants were harvested and assayed by capture ELISA in triplicate. Mice treated with $\alpha 4$-api showed decreased levels of IL-10 and increased production of IL-18 ( $P$ $<0.05)$. Results are expressed as the mean \pm SD and are representative of 15 animals in the treated group and 10 animals in the control group.

effect observed was at least partly caused by an inhibition of the skin response itself.

\section{Effect of Blockade of $\alpha 4$-Integrin Interactions with Its Ligands on the Th2 Shift}

It has been shown that a shift to a Th2 cytokine profile can result in a decrease in incidence and severity of EAU, without a significant effect in the lymphoproliferative response to retinal antigens. ${ }^{42,43}$ Draining lymph node cells from $\alpha 4$-apitreated or control mice were harvested 21 days after immunization and assayed for cytokine levels in supernatants from IRBP-stimulated cells. Although treatment with $\alpha 4$-api had no effect on the production of IFN- $\gamma$, increased amounts of IL-18 were observed (Fig. 5). In all experiments both IL-4 and -5 levels were at or below the detection limit (data not shown). Moreover, the production of IL-10 was decreased when compared with that in the control group, and no differences were observed in IL-12 secretion between the groups (Fig. 5). Our data thus indicate that amelioration of EAU induced by treatment with $\alpha 4$-api is not associated with a shift in cytokine profile. Treatment in the afferent phase did not influence cytokine synthesis (data not shown). However, because of the experimental system used, we cannot rule out that the changes observed are fleeting; and because cytokine measurements were performed more than 2 weeks after the last administration of the inhibitor, these may not have persisted long enough to be noticed at the time point of the measurements.

Nevertheless, it is still possible that a minor or transient change in the cytokine profile would not necessarily translate into in vitro cytokine synthesis. We have shown that antigenspecific antibody isotypes are good indicators of the cytokines secreted during an immune response. ${ }^{40,43}$ Because IFN- $\gamma$ and IL-4 promote immunoglobulin (Ig) isotype switching to IgG2a and IgG1, the relative amounts of these isotypes in mice sera may reflect the balance between Th1 and Th2 responses. Our results show that treatment with $\alpha 4$-api does not affect antiIRBP IgG2a antibodies, although anti-IRBP IgG1 was decreased in the $\alpha 4$-api-treated animals compared with the control (Fig. 6 ), supporting the in vitro data on cytokine production after this treatment. Taken together, our results suggest that VLA-4 blockade does not inhibit EAU by either changing the cytokine profile of the retinal antigen-specific $\mathrm{T}$ cells or by silencing them, but probably by blocking their recruitment to the inflammatory site.

\section{Discussion}

The murine model of EAU was established several years ago ${ }^{39}$ and is thought to be a representative model for the study of therapeutic approaches to human posterior uveitis. Studies of genetic susceptibility and resistance to EAU, ${ }^{44}$ identification of uveitogenic epitopes, ${ }^{38}$ and induction of tolerance to $\mathrm{EAU}^{45-48}$ have been successfully performed in this model.

During EAU, immune cells infiltrate the parenchyma of the eye and exert their destructive effects on the retina and choroid. The process of cell recruitment to the eye involves a series of cell-to-cell interactions, in both the vasculature and ocular tissues. Although the requirement for $\alpha 4$-integrins in cell recruitment to the retina has been well established, ${ }^{49-51}$ the precise role of these receptors at different steps of this process has not been clearly defined. In the present study, we show that treatment with the modified peptide $\alpha 4$-api reduces the severity of clinical signs of EAU, as well as and cell recruitment into the eye.

Although treatment with $\alpha 4$-api was effective in decreasing the signs of EAU, it is noteworthy that it did not significantly change the cytokine balance toward a Th2 profile, a characteristic commonly seen on remission in the evolution of this disease. It is also notable that production of IL-18 was increased in the $\alpha 4$-api-treated group compared with the control mice. Moreover, mice treated with the inhibitor at the afferent phase showed enhanced levels of this cytokine in supernatants of IRBP-specific lymph node cell cultures (data not shown). IL-18 is secreted by activated macrophages and dendritic cells and acts synergistically with IL-12 to induce IFN- $\gamma$ secretion by T cells $^{52}$ or NK cells. ${ }^{53}$ IL-18 has been also shown to upregulate the expression of ICAM-1 and VCAM-1 on endothelial cells and synovial fibroblasts from patients with rheumatoid arthritis. ${ }^{54}$ In our model, the overproduction of IL-18 in $\alpha 4$-api-treated treated mice gave rise to two possibilities. The first suggests that macrophages that have been activated after immunization and migrated to the lymph nodes before treatment with VLA-4 inhibitor are the main source of IL-18. Because these cells are trapped in this organ, it seems reasonable to assume that the

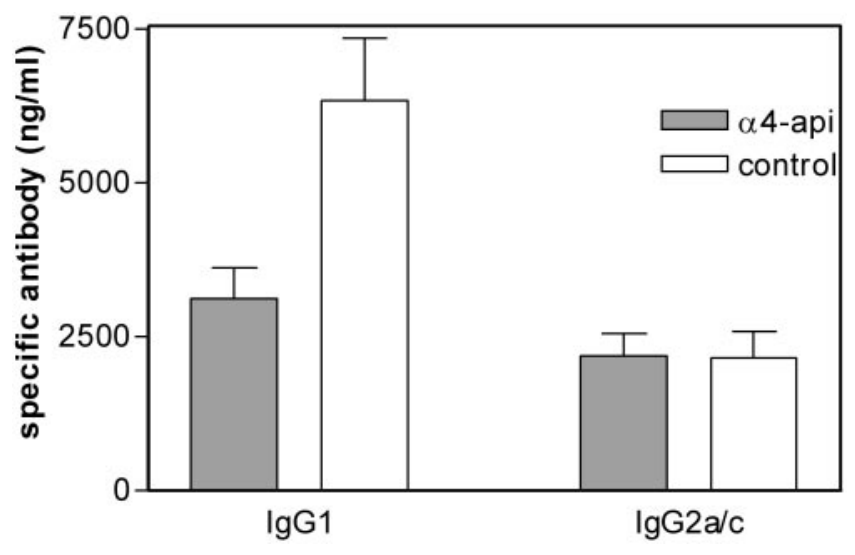

Figure 6. Anti-IRBP IgG1- and IgG2a/c-specific isotypes in B10.RIII mice treated or not treated with an $\alpha 4$ peptide inhibitor at the efferent phase. Immunoglobulins bound to IRBP-coated plates were quantified by isotype-specific ELISA. Mice treated with $\alpha 4$-api showed decreased production of anti-IRBP IgG1 as compared to the control $(P<0.05)$. Results are expressed as the mean \pm SD and are representative of 15 animals in the treated group and 10 animals in the control group. 
secretion of IL-18 is enhanced because of the increasing number of accumulating activated cells in these mice compared with that in the control animals. Another possible explanation is that the increased production of IL-18 enhances the expression of VCAM-1 on endothelial cells as a mechanism of positive regulation because of the lack of interaction of these molecules with VLA-4. One would expect that increased levels of IL-18 would be reflected by an enhanced secretion of IFN- $\gamma$. Because there were no differences in IL-12 production between both groups, one may hypothesize that IL-18 alone would not be sufficient to enhance the production of IFN- $\gamma$. Another possibility is that IFN- $\gamma$ has reached its saturation levels and therefore maintained its production pattern.

Investigation of the production of anti-IRBP IgG1 and IgG2a isotypes as markers of T2- and T1-type cytokines, respectively, reinforces the notion that treatment with the VLA- 4 inhibitor did not induce a shift toward a Th2 profile, since the levels of IgG1 were even lower when compared with those in control animals. Canella et al. ${ }^{55}$ showed that in EAE, treatment with another peptide inhibitor of VLA- 4 results in amelioration of the disease if the peptide is administered in the acute phase of the disease. This phenomenon is due to changes in the proinflammatory cytokine profile as a consequence of an increase in Th2 cytokines. Of note, their animals did not exhibit EAE, even after cessation of the treatment. In our model, treatment with an $\alpha 4$-integrin-blocking peptide was effective in the suppression of uveitis when used in the efferent phase of the disease, which is characterized by inflammatory infiltrates in the eye of activated cells. We observed suppression of the disease 21 days after immunization, and our results strongly suggest that amelioration of uveitis is dependent on the frequency of the administration of the peptide. Furthermore, in our model we did not see any changes in the cytokine pattern, which showed no skewing toward the Th2 profile. Therefore, it is plausible to assume that, different from the results obtained in EAE, the administration of this peptide does not affect the expansion of autoreactive cells and therefore does not interfere with the pool of cells potentially capable of migrating to the eye.

VLA- 4 is a known cell adhesion molecule, adhering to lymphocytes, that interacts with VCAM-1 and can induce activation and proliferation. ${ }^{32,56}$ Blockade of VLA- 4 by small-molecule inhibitors could interfere with this process, as it has been shown in human T lymphocytes. ${ }^{57,58}$ Indeed, earlier studies have indicated that blockade of T-cell activation suppresses the clinical signs of EAU. ${ }^{59,60}$

The $\alpha 4$-integrin-blocking peptide was also efficient in suppressing the development of EAU in the adoptive transfer model. Decreasing disease grades were significant in treated animals. In this model, the migration of uveitogenic $\mathrm{T}$ lymphocytes across the endothelium of the BRB occurred in a relatively short time span, without the continuous induction of uveitogenic $T$ cells by the prolonged presence of antigen as in actively induced EAU. This finding indicates that $\alpha 4$ integrins are indeed essential in the recruitment of lymphocytes into the eye, as suggested previously, ${ }^{22}$ and that blockade of integrinligand interactions may be effective in preventing the entry of uveitogenic cells.

In our model, inhibition of leukocyte migration by treatment with anti-VLA-4 was also demonstrated by suppressed DTH reaction in these animals. Previous reports have shown that DTH responses to IRBP in $\mathrm{C} 57 \mathrm{BL} / 6$ immunized mice are characterized by the presence of a mononuclear cell infiltrate. ${ }^{60}$ Although we have not evaluated the cell profile that migrated to the lesions in control mice, minimal DTH responses in $\alpha 4$-api-treated mice may be a consequence of migration of cells that interact with the endothelia by adhesion molecules different from VLA- 4 . Moreover, the proliferative response to IRBP was not affected in anti-VLA-4-treated mice, which strongly suggests that suppression of the clinical signs of EAU in our study was mainly associated with the inhibition of cell migration rather than a suppression of the immune response to the specific antigen.

The precise nature of the $\alpha 4$-integrin ligand blocked by the inhibitory peptide is not completely clear. VCAM-1 expression in the eye was only observed on blood vessels adjacent to histopathological lesions and in RPE cells in patients with uveitis. VCAM-1 was upregulated after incubation with TNF- $\alpha$, IFN- $\gamma$, and IL- $1 \beta$, indicating that this molecule is not constitutively expressed at the cell surface. ${ }^{58}$ The other known $\alpha 4$ ligand is the CS1 domain found in alternatively spliced forms of Fn. Although there are no data about this ligand in the eye, increased Fn expression has been found in the retinal vessels of S-antigen-induced uveitis 1 to 2 days before the histologic and clinical onset of EAU. ${ }^{61}$ Fn expression has also been observed in the vascular basement membrane of the iris and in the retinal vascular basement membrane in EAU in rats. ${ }^{61,62}$

In addition, a weak positivity for the CS1 domain has been observed in blood vessels of CNS tissue during EAE, whereas abundant expression has been observed on astrocytes in both naive and EAE animals. Van der Laan et al. ${ }^{26}$ postulated that the CS1-ligand motif expressed by astrocytes functions as a ligand for VLA-4-positive leukocytes, as confirmed by in vitro experiments in which the interaction between primary rat lymphocytes and astrocytes was substantially blocked by an $\alpha 4$ inhibitory peptide. The lack of cellular infiltrates in transferred EAE in animals treated with $\alpha 4$-api may be caused by the lack of adherence of transferred T cells to the astrocyte CS1 domain, rather than from the lack of binding to VCAM-1.

In summary, in the current study, blockade of $\alpha 4$ integrins had a beneficial effect on actively induced EAU. The recruitment of T cells may involve interactions with VCAM-1 and CS-1 Fn. Furthermore, the use of $\alpha 4$ inhibitors may contribute as an alternative therapeutic approach in the control autoimmune ocular diseases.

\section{References}

1. Caspi RR, Roberge FG, McAllister CG, et al. T cell lines mediating experimental autoimmune uveoretinitis (EAU) in the rat. $J$ Immunol. 1986;136:928-933.

2. Gery I, Mochizuki M, Nussenblatt RB. Retinal specific antigens and immunopathogenic processes they provoke. In: Osborne NN, Chader GJ, eds. Progress in Retinal Research. Oxford, UK: Pergamon Press, 1986;75-109.

3. Forrester JV. Uveitis pathogenesis. Lancet. 1991;338:1498-1501.

4. Caspi RR, Chan CC, Fujino Y, et al. Recruitment of antigen-nonspecific cells plays a pivotal role in the pathogenesis of a $\mathrm{T}$ cell-mediated organ-specific autoimmune disease, experimental autoimmune uveoretinitis. J Neuroimmunol. 1993;47:177-188.

5. Chan CC, Caspi RR, Ni M, et al. Pathology of experimental autoimmune uveoretinitis in mice. J Autoimmun. 1990;3:247-255.

6. Caspi RR, Chan CC, Leake WC, Higuchi M, Wiggert B, Chader GJ. Experimental autoimmune uveoretinitis in mice: induction by a single eliciting event and dependence on quantitative parameters of immunization. J Autoimmun. 1990;3:237-246.

7. Springer TA. Traffic signals for lymphocyte recirculation and leukocyte emigration: the multistep paradigm. Cell. 1994;76:301-314.

8. Springer TA. Traffic signals on endothelium for lymphocyte recirculation and leukocyte emigration. Annu Rev Physiol. 1995;57: 827-872.

9. Prendergast RA, Iliff CE, Coskuncan NM, et al. T cell traffic and the inflammatory response in experimental autoimmune uveoretinitis. Invest Ophthalmol Vis Sci. 1998;39:754-762.

10. Devine L, Lightman S, Greenwood J. Lymphocyte migration across the anterior and posterior blood-retinal barrier in vitro. Cell Immunol. 1996;168:267-275. 
11. Devine L, Lightman SL, Greenwood J. Role of LFA-1, ICAM-1, VLA-4 and VCAM-1 in lymphocyte migration across retinal pigment epithelial monolayers in vitro. Immunology. 1996;88:456-462.

12. Greenwood J. The blood-retinal barrier in experimental autoimmune uveitis (EAU): a review. Curr Eye Res. 1992;11(suppl):2532.

13. Atalla L, Linker-Israeli M, Steinman L, Rao NA. Inhibition of autoimmune uveitis by anti-CD4+antibody. Invest Ophthalmol Vis Sci. 1990;31:1264-1270.

14. Jiang H, Lumsden L, Forrester JV. Macrophages and dendritic cells in IRBP-induced experimental autoimmune uveoretinitis in B10RIII Mice. Invest Ophthalmol Vis Sci. 1999;40:3177-3185.

15. Baron JL, Madri JA, Ruddle NH, Hashim G, Janeway CA Jr. Surface expression of $\alpha 4$ integrin by CD4 T cells is required for their entry into the brain parenchyma. J Exp Med. 1993;177:57-68

16. Steffen BJ, Butcher EC, Engelhardt B. Evidence for involvement of ICAM-1 and VCAM-1 in lymphocyte interaction with endothelium in experimental autoimmune encephalomyelitis in the central nervous system in the SJL/J mouse. Am J Pathol. 1994;145:189-201.

17. Brocke S, Piercy C, Steinman L, Weissman IL, Veromaa T. Antibodies to CD 44 and integrin $\alpha 4$, but not L-selectin, prevent central nervous system inflammation and experimental encephalomyelitis by blocking secondary leukocyte recruitment. Proc Natl Acad Sci USA. 1999;96:6896-6901.

18. Yednock T, Cannon C, Fritz LC, Sanchez-Madrid F, Steinman L, Karin N. Prevention of experimental autoimmune encephalomyelitis by antibodies against alpha 4 beta 1 integrin. Nature. 1992; 356:63-66.

19. La Heij E, Kiujpers RW, Baarsma S, Kijlstra A, van der Weiden M Mooy CM. Adhesion molecules in iris biopsy specimens from patients with uveitis. Br J Ophthalmol. 1998;82:432- 437.

20. Hill TA, Stanford MR, Graham EM, Dumonde DC, Brown KA. A new method for studying the selective adherence of blood lymphocytes to the microvasculature of human retina. Invest Ophthalmol Vis Sci. 1997;38:2608-2618.

21. Hill TA, Stanford MR, Graham EM, Dumonde DC, Brown KA. A new method for studying the selective adherence of blood lymphocytes to the microvasculature of human retina. Invest Ophthalmol Vis Sci. 1997;38:2608-2618.

22. Whitcup SM, DeBarge LR, Caspi RR, Harning R, Nussenblatt RB, Chan CC. Monoclonal antibodies against ICAM-1 (CD54) and LFA-1 (CD11a/CD18) inhibit experimental autoimmune uveitis. Clin Immunol Immunopathol. 1993;67:143-150.

23. Devine L, Lightman SL, Greenwood J. Role of LFA-1, ICAM-1, VLA-4 and VCAM-1 in lymphocyte migration across retinal pigment epithelial monolayers in vitro. Immunology. 1996;88:456-462.

24. Wayner EA, Garcia-Pardo A, Humphries MJ, McDonald JA, Carter WG. Identification and characterization of the T lymphocyte adhesion receptor for an alternative cell attachment domain (CS-1) in plasma fibronectin. J Cell Biol. 1989;109:1321-1330.

25. Elices MJ, Osborn L, Takada Y, Crouse C, Luhowskyj S, Hemler ME VCAM-1 on activated endothelium interacts with the leukocyte integrin VLA- 4 at a site distinct from the VLA-4/fibronectin binding site. Cell. 1990;60:577-584.

26. Van der Laan LJW, De Groot CJA, Elices MJ, Dijkstra CD. Extracellular matrix proteins expressed by human adult astrocytes in vivo and in vitro: an astrocyte surface protein containing the CS1 domain contributes to binding of lymphoblasts. J Neurosci Res. 1997;50:539-548.

27. Wahl S, Allen J, Hines K, Imamichi T, Wahl A, Furcht L. Synthetic fibronectin peptides suppress arthritis in rats by interrupting leukocyte adhesion and recruitment. J Clin Invest. 1994;94:655-662.

28. Martín AP, Ortiz S, Cabalier MED, et al. Vascular endothelium express CS-1 fibronectin in allergic contact dermatitis. J Cutan Pathol. 2002;29:347-353.

29. May MJ, Entwistle G, Humphries MJ, Ager A. VCAM-1 is a CS1 peptide-inhibitable adhesion molecule expressed by lymph node high endothelial. J Cell Sci. 1993;106:109-119.

30. Makarem R, Newham P, Askari JA, Green LJ, Clements J, Edwards M. Competitive binding of vascular cell adhesion molecule- 1 and the HepII/IIICS domain of fibronectin to the integrin $\alpha 4 \beta 1$. J Biol Chem. 1994;269:4005-4011.
31. Clements JM, Newham P, Shepherd M, Gilbert R, Dudgeon TJ, Lindsey A. Identification of a key integrin-binding sequence in VCAM-1 homologous to the LDV active site in fibronectin. $J$ Cell Sci. 1994;107:2127-2135.

32. Kuijpers TW. Pathophysiological aspects of VLA-4 interactions and possibilities for therapeutical interventions. Springer Semin Immunopathol. 1995;16:379-389.

33. Lobb RR, Hemler ME. The pathophysiologic role of $\alpha 4$ integrins in vivo. J Clin Invest. 1994;94:1722-1728.

34. Molossi S, Elices M, Arrhenius T, Diaz R, Coulber C, Rabinovitch M. Blockade of very late antigen- 4 integrin binding to fibronectin with connecting segment-1 peptide reduces accelerated coronary arteriopathy in rabbit cardiac allografts. J Clin Invest. 1995;95:26012610.

35. Tamraz S, Arrhenius T, Chien A, Forrest MJ, Gaeta FCA, He Y-B. Treatment of delay-type hypersensitivity with inhibitors of the VLA-4 integrin. Springer Semin Immunopathol. 1995;16:437441

36. Van der Laan LJW, Van der Goes A, Wauben MH, et al. Beneficial effect of modified peptide inhibitor of $\alpha_{4}$ integrins on experimental allergic encephalomyelitis in Lewis rats. J Neurosci Res. 2002; 67:191-199.

37. Rizzo LV, Silver P, Wiggert B, et al. Establishment and characterization of a murine $\mathrm{CD} 4+\mathrm{T}$ cell line and clone that induce experimental autoimmune uveoretinitis in B10.A mice. J Immunol. 1996;156:1654-1660.

38. Silver PB, Rizzo LV, Chan CC, Donoso LA, Wiggert B, Caspi RR. Identification of a major pathogenic epitope in the human IRBP molecule recognized by mice of the $\mathrm{H}-2 \mathrm{r}$ haplotype. Invest $O p h$ thalmol Vis Sci. 1995;36:946-954.

39. Caspi RR, Roberge FG, Chan CC, et al. A new model of autoimmune disease: experimental autoimmune uveoretinitis induced in mice with two different retinal antigens. J Immunol. 1988;140: $1490-1495$.

40. Rizzo LV, DeKruyff RH, Umetsu DT, Caspi RR. Regulation of the interaction between Th1 and Th2 T cell clones to provide help for antibody production in vivo. Eur J Immunol. 1995;25:708-716.

41. Snedecor GW, Cochran WG. Statistical Methods. Ames, IA: Iowa State University Press; 1967:248.

42. Saoudi A, Kuhn J, Huygen K, et al. TH2 activated cells prevent experimental autoimmune uveoretinitis, a TH1-dependent autoimmune disease. Eur J Immunol. 1993;23:3096-3103.

43. Sun B, Rizzo LV, Sun SH, Caspi RR. Genetic susceptibility to experimental autoimmune uveitis involves more than a predisposition to generate a Th1-like or a Th2-like response. J Immunol. 1997;159:1004-1011.

44. Caspi RR, Grubbs BG, Chan CC, Chader GJ, Wiggert B. Genetic control of susceptibility to experimental autoimmune uveoretinitis in the mouse model: concomitant regulation by MHC and nonMHC genes. J Immunol. 1992;148:2384-2388.

45. Hara Y, Caspi RR, Wiggert B, Chan CC, Wilbanks GA, Streilein JW. Suppression of experimental autoimmune uveitis in mice by induction of anterior chamber-associated immune deviation with interphotoreceptor retinoid-binding protein. J Immunol. 1992; 148:1685-1692.

46. Hara Y, Caspi RR, Wiggert B, Chan CC, Streilen JW. Use of ACAID to suppress interphotoreceptor retinoid binding protein-induced experimental autoimmune uveitis. Curr Eye Res. 1992;11(suppl): 97-100

47. Thurau SR, Chan CC, Nussenblatt RB, Caspi RR. Oral tolerance in a murine model of relapsing experimental autoimmune uveoretinitis (EAU): induction of protective tolerance in primed animals. Clin Exp Immunol. 1997;109:370 -376.

48. Rizzo LV, Miller-Rivero NE, Chan CC, Wiggert B, Nussenblatt RB, Caspi RR. Interleukin 2 treatment potentiates induction of oral tolerance in a murine model of autoimmunity. J Clin Inv. 1994; 94:1668-1672.

49. Clegg DO, Mullick LH, Wingerd KL, et al. Adhesive events in retinal development and function: the role of integrin receptors. Results Probl Cell Differ. 2000;31:141-156.

50. Rose DM, Han J, Ginsberg MH. Alpha4 integrins and the immune response. Immunol Rev. 2002;186:118-124. 
51. Rose DM, Grabovsky V, Alon R, Ginsberg MH. The affinity of integrin alpha(4)beta(1) governs lymphocyte migration. J Immunol. 2001;167:2824-2830.

52. Micallef M, Ohtsuki T, Kohno K, et al. Interferon- $\gamma$-inducing factor enhances T helper 1 cytokine production by stimulated human $\mathrm{T}$ cells: synergism with interleukin-12 for interferon- $\gamma$ production. Eur J Immunol. 1996;26:1647-1651.

53. Zhang T, Kawakami K, Qureshi MH, Okamura H, Kurimoto M, Saito A. Interleukin-12 (IL-12) and IL-18 synergistically induce the fungicidal activity of murine peritoneal exudates cells against Cryptococcus neoformans through production of gamma interferon by natural killer cells. Infect Immun. 1997;65:3594-3599.

54. Morel JC, Park CC, Woods JM, Koch AE. A novel role for interleukin-18 in adhesion molecule induction through NF kappa B and phosphatidylinositol (PI) 3-kinase-dependent signal transduction pathways. J Biol Chem. 2001;276:37069-37075.

55. Canella B, Gaupp S, Tilton RG, Raine CS. Differential efficacy of a synthetic antagonist of VLA- 4 during the course of chronic relapsing experimental autoimmune encephalomyelitis. J Neurosci Res. 2003;71:407-416.

56. Ando K, Fujino Y, Mochizuki M. Effects of monoclonal antibodies directed at cell surface molecules on murine experimental autoimmune uveoretinitis. Graefes Arch Clin Exp Ophthalmol. 1999; $237: 848-854$.
57. McIntyre BW, Woodsite DG, Caruso DA, Wooten DK, Simon SI, Neelamegham S. Regulation of human T lymphocyte coactivation with an $\alpha 4$ integrin antagonist peptide. J Immunol. 1997;158: $4180-4186$.

58. Platts KE, Benson MT, Rennie IG, Sharrard RM, Rees RC. Cytokine modulation of adhesion molecule expression on human retinal pigment epithelial cells. Invest Ophthalmol Vis Sci. 1995;36: 2262-2269.

59. Silver PB, Hathcock KS, Chan CC, Wiggert B, Caspi RR. Blockade of costimulation through $\mathrm{B} 7 / \mathrm{CD} 28$ inhibits experimental autoimmune uveoretinitis, but does not induce long-term tolerance. J Immunol. 2000;165:5041-5047.

60. Jones LS, Rizzo LV, Agarwal RK, et al. IFN- $\gamma$-deficient mice development experimental autoimmune uveitis in the context of a deviant effector response. J Immunol. 1997;158:5997-6005.

61. Fujikawa LS, Chan CC, McAllister C, et al. Retinal vascular endothelium expresses fibronectin and class II histocompatibility complex antigens in experimental autoimmune uveitis. Cell Immunol. 1987;106:139-150.

62. Wang J, Lin WL, Essner E, Shichi H, Yelian FD. Ultrastructural and immunocytochemical studies of iris vessels in rats with experimental autoimmune uveoretinitis. Curr Eye Res. 1994;13: 747-754 